\title{
Implementation of recommendations for the care of children in UK emergency departments: national postal questionnaire survey
}

\author{
R Salter, I K Maconochie
}

In June 1999 an intercollegiate working party of Royal College of Paediatrics and Child Health, British Association of Accident and Emergency Medicine (BAEM), British Association of Paediatric Surgeons, Faculty of Accident and Emergency Medicine, Royal College of Nursing (RCN), and Royal College of General Practitioners was established. Terms of reference were to review emergency services for children and to make recommendations for future provision of these services. The subsequent report-Accident and Emergency Services for Children (AESC)-made 32 recommendations (representing minimum levels of care), to be implemented by 2004 .

\section{Participants, methods, and results}

We sent questionnaires to lead emergency doctors (listed in the BAEM's directory of 2001-2) between Oct 2003 and Jan 2004 about the recommendations. Nonresponders were re-sent the questionnaire.

Facilities, function, and staffing of 139 UK paediatric emergency departments

No $(\%)$ of responses from the targeted UK emergency departments

\begin{tabular}{lc}
\hline Facilities & \\
\hline $\begin{array}{l}\text { Trusts where children may be seen first for emergency } \\
\text { conditions outside the emergency department }\end{array}$ & $95(61)$ \\
\hline With triage and resuscitation facilities & $56(35)$ \\
\hline Function & $36(22.9)$ \\
\hline Separate paediatric triage & $143(90)$ \\
\hline Triage by trained nurse & $129(82)$ \\
\hline Pain score used at triage & $113(70)$ \\
\hline National triage scale used & $14(10.1)$ \\
\hline All paediatric surgical cases can be managed on site & $24(15)$ \\
\hline Provision for children in major incident plan* & $104(64)$ \\
\hline Ability to maintain level 2 care $\dagger$ & $147(94)$ \\
\hline Adequate audiovisual separation & $123(78)$ \\
\hline Play area or separate waiting area & $131(82)$ \\
\hline Paediatric resuscitation area screened from adult patients & $28(17.8)$ \\
\hline Patient information & $107(68)$ \\
\hline Leaflets available in languages other than English & $113(72)$ \\
\hline Staffing: nursing & $84(53)$ \\
\hline Not having at least one children's trained nurse on \\
duty at all times \\
\hline Senior nurse coordinating \\
\hline Nurses attended paediatric advanced life support course \\
\hline Staffing: medical & $102(64)$ \\
\hline No of consultants with recognised training & $129(90)$ \\
\hline In departments $>18$ 000 children a year & $120(87)$ \\
\hline Designated liaison paediatrician & \\
\hline Interaction with other agencies & \\
\hline Induction programme including child protection \\
\hline Bereavement policy
\end{tabular}

* Nine $(7 \%)$ did not know if children were included in the major incident plan. tLevel 2 care is continuous nursing supervision where the patient may be ventilated and needs support of two or more organ systems.
Of 219 departments with inpatient paediatric facilities, ${ }^{2} 139(63 \%)$ replied (table). In all, $47(34 \%)$ of replying hospitals saw more than 18000 children annually; 41 (87\%) were district general hospitals. Only 64 (29\%) departments with separate paediatric emergency facilities responded; the $71 \%$ that did not respond accounted for $47 \%$ of nonresponders, many seeing more than 18000 children annually.

Although currently 41 departments have separate paediatric emergency departments, 92\% of children attend general departments; these show the largest differences from recommendations of the AESC report. In 1997, 10\% of hospitals did not have inpatient services onsite ${ }^{3}$ now only $1.9 \%$ do not (minor injury units excluded).

Wards are safe for only the initial reception of emergency admissions if appropriately equipped and staffed for reception, triage, and resuscitation ${ }^{1}$; these criteria are often not met.

Assessing the severity of illness is essential, but a quarter of departments seeing more than 18000 children a year do not have separate triage facilities, and 23\% do not triage children with an appropriately trained nurse. Although the pain assessment tool and the national triage score are used widely, their effectiveness must be questioned where nontrained staff are triaging. Level 2 care, while awaiting a paediatric retrieval team (children's mobile intensive care unit), is delivered in $85 \%$ of departments, often at cost to emergency, paediatric, and intensive care services. The current trend of centralisation means that emergency staff must deliver this care, so there must be the appropriate mix of skills on duty.

In 1996, 30\% of hospitals did not cater for children within major incident plans (required by the National Service Framework for children and young people $)^{4}$; fewer now have children in their plans.

The National Service Framework expects emergency professionals to do courses in paediatric life support and to regularly update; currently, $47 \%$ of nurses do not attend such courses.

\section{Comment}

One in four patients presenting at emergency departments is a child. Child centred good quality care which is accessible at the right time is required, however there is considerable room for improvement in the care of children in emergency departments. This government

\section{This article was posted on bmj.com on 3 December 2004:} http://bmj.com/cgi/doi/10.1136/bmj.38313.580324.F7

\section{The questionnaire is on bmj.com}

Department of

Paediatric Accident and Emergency,

St Mary's Hospital, London W2 1NY

R Salter

specialist registrar in

paediatric emergency

medicine

I K Maconochie

consultant in

paediatric emergency

medicine

Correspondence to:

R Salter

beckyparas@

aol.com

BMJ 2005;330:73-4 


\section{What is already known on this topic}

Paediatric emergency services were under resourced in the United Kingdom, a report in 1999 found; the report made recommendations for improvement

\section{What this study adds}

Current emergency services for children in the United Kingdom still fall short of these essential recommendations

has recognised unacceptable variations nationwide in the quality of care for children and wants to eliminate these differences (the National Service Framework). ${ }^{4}$ The framework allows adult nurses to care for children only within the limits of their knowledge and should be under direct supervision of a children's trained nurse. Recruitment and retention of nursing staff is a problem in emergency departments. The Royal College of Nursing recommends rotational posts with community nursing and paediatric wards. The number of applicants for training in children's nursing exceeds the number available, so structured investment in nurse training may provide the necessary skilled nurses.
The AESC recommends that hospitals seeing more than 18000 children should have a consultant in paediatric emergency medicine by 2004 and in all emergency departments by 2010. This, along with many of the other AESC recommendations made five years ago, has not been met and without future investment in staffing and facilities a child centred service will be hard to achieve.

Contributors: RS was the primary investigator. IKM was supervisor. IKM is guarantor.

Funding: St Mary's Hospital NHS Trust, department of Paediatric Accident and Emergency.

Competing interests: None declared.

Ethical approval: Not needed.

Royal College of Paediatrics and Child Health. Accident and emergenc services for children: a report of a multidisciplinary working party. London: $\mathrm{RCPCH}, 1999$.

Royal College of Paediatrics and Child Health. Providing a service for chidren:workforce census 2001. London: RCPCH, 2003.

Action for Sick Children. Emergency health services for children and youn people: a guide for commissioners and providers. London: ASC, 1997.

Carly SD Jones M. Are we ready for the next major incident? A review of hospital major incident plans. BMJ 1996;313:1242-3.

-3. 5 Department of Health. Getting the right start: the national service framework for children, young people and maternity services: standard for hospital services. London: DoH, 2003.

(Accepted 15 November 2004)

doi 10.1136/bmj.38313.580324.F7

\section{DRUG POINTS}

\section{Synovitis induced by alendronic acid can present as acute carpal tunnel syndrome}

David Gwynne Jones, Ruth Savage, John Highton

Department of Orthopaedic Surgery, Dunedin Hospital, Great King Street, Dunedin, 9001, New Zealand David Gwynne Jones consultant orthopaedic surgeon

Department of Rheumatology,

Dunedin Hospital John Highton associate professor of rheumatology

Centre for Adverse Reactions

Monitoring, New

Zealand

Pharmacovigilance

Centre, PO Box 913

Dunedin

Ruth Savage

senior research fellow

Correspondence to: D Gwynne Jones

David.gwynne-jones@

stonebow.otago.ac.nz

BMJ 2005;330:74
Alendronic acid (Fosamax, Merck) is a potent oral bisphosphonate licensed for prevention ( $5 \mathrm{mg}$ daily) and treatment of postmenopausal osteoporosis $(70 \mathrm{mg}$ weekly or $10 \mathrm{mg}$ daily). ${ }^{1}$

A 69 year old woman had been treated for osteoporosis with disodium etidronate (Didronel, Procter \& Gamble) for four years. She had a history of asthma but was not taking prednisolone. She started taking $70 \mathrm{mg}$ alendronic acid a week but within 24 hours of her first dose developed synovitis in her right wrist and within 72 hours developed acute carpal tunnel syndrome. Fluid was found in the carpal tunnel when it was decompressed. No organisms or crystals were seen. Laboratory tests have included a consistently normal $\mathrm{C}$ reactive protein and erythrocyte sedimentation rate, calcium $2.41 \mathrm{mmol} / \mathrm{l}$, ferritin $39 \mu \mathrm{g} / \mathrm{l}$, uric acid $0.3 \mathrm{mmol} / \mathrm{l}$, antinuclear antibodies $1 / 80$, and negative extractable nuclear antigens, double stranded DNA, and rheumatoid factor. Nerve conduction studies showed a marked axonal lesion in the sensory median nerve. Alendronic acid was restarted at $10 \mathrm{mg}$ daily five months later, but she developed pain in multiple joints after three days. The symptoms recurred on rechallenge at $10 \mathrm{mg}$ on alternate days. She recovered fully when alendronic acid was discontinued.

\section{Discussion}

Synovitis is a well recognised cause of carpal tunnel syndrome. This patient had no previous history of carpal tunnel syndrome or evidence of inflammatory arthritis. Rechallenge led to symptoms in multiple joints.

Alendronic acid can cause musculoskeletal pain. ${ }^{2}$

The New Zealand Pharmacovigilance Centre (http://carm.otago.ac.nz) holds three other reports of synovitis occurring in patients taking alendronic acid, one of whom developed a wrist effusion. Synovitis recurred when alendronic acid was re-administered after the normal dose interval of seven days in two patients and at a reduced dose after 11 days in the third. Alendronic acid should be considered a cause of synovitis or polyarthritis in the absence of any other pathology.

Contributors: DGJ identified and managed the case surgically, and $\mathrm{JH}$ investigated and managed the patient medically. DGJ and RS searched the literature, and RS collated and summarised other adverse reactions. DGJ is guarantor.

Funding: None.

Competing interests: None declared.

Bisphosphonates for osteoporosis. Drug Ther Bull 2001:39:68-72.

Sharpe M, Noble S, Spencer CM. Alendronate: an update on its use in osteoporosis. Drugs 2001;61:999-1039. 